\title{
Percent of Necrosis
}

National Cancer Institute

\section{Source}

National Cancer Institute. Percent of Necrosis. NCI Thesaurus. Code C159481.

A quantitative measurement of the percent of cells undergoing necrosis compared to the number of total cells present in a sample. 